\title{
LETRAMENTO E ENSINO DE LÍNGUA PORTUGUESA: UMA EXPERIÊNCIA E MÚLTIPLOS APRENDIZADOS
}

\begin{abstract}
Luciano Taveira de Azevedo (ETEPAM) interessa-se por pesquisas na área de Linguística Aplicada com foco em ensino de língua portuguesa para brasileiros e estrangeiros. É Mestre pela Universidade Federal de Alagoas e, em dissertação defendida em fevereiro de 2010, ocupou-se das atividades de leitura em coleção didática do Ensino Médio. Atualmente, leciona as disciplinas de Língua Portuguesa e Literatura na Escola Estadual Professor Agamemnon Magalhães, onde realiza diferentes projetos e intervenções no sentido de levar o estudante do Ensino Médio a apropriar-se dos mecanismos da língua em diferentes contextos.

E-mail: lucianoazevedo7@gmail.com
\end{abstract}

\section{Resumo}

Neste relato de experiência, nós apresentamos os resultados obtidos durante a vivência de um projeto de letramento na disciplina de Língua Portuguesa com alunos do $1^{\circ}$ ano do Ensino Médio Integrado ao Técnico da Escola Professor Agamemnon Magalhães. Buscamos apoio teórico nas reflexões desenvolvidas por Kleiman (1995), Antunes (2003), Bakhtin (2006) e Schneuwly e Dolz (2010) sobre gêneros textuais, leitura e produção de textos. Com base nesses autores, assumimos uma perspectiva sociodiscursiva e interacionista da linguagem. $\mathrm{O}$ projeto teve como objetivo intervir no processo de ensinoaprendizagem de leitura e produção textual, uma vez que foram identificadas deficiências relativas ao reconhecimento do gênero textual, uso adequado das relações morfossintáticas, leitura expressiva e compreensão textual. Ao longo da vivência do projeto, os estudantes foram expostos a diferentes gêneros textuais e situações sociocomunicativas que contribuíram para amenizar ou solucionar as deficiências identificadas. $\mathrm{O}$ projeto de letramento recebeu o nome de Luiz Gonzaga Canta o Sertão Nordestino.

\begin{abstract}
In this experience report, we present the results obtained during the experience of a literacy project in the discipline of Portuguese with students from 1st year of Integrated Technical High School Teacher Agamemnon Magalhães (Professor Agamemnon Magalhães) . We looked for support in theoretical reflections developed by Kleiman (1995), Ali (2003), Bakhtin (2006) and Schneuwly and Dolz (2010) on textual genres, reading and producing texts. Based on these authors, we assumed a sociodiscursive and interactionist perspective of language. The project had as objective to intervene in the teaching and learning of reading and textual production since disabilities have been identified in recognition of the textual genre, the appropriate use of morphosyntactic relations, expressive reading and text comprehension. Throughout the experience of the project, the students were exposed to different textual genres and sociocommunicative situations that contributed to minimize or resolve the identified deficiencies. The literacy project was named Luiz Gonzaga Sings the Northeastern Hinterland.
\end{abstract}

\section{1) Introdução}

Em 2011, fui convidado pela gestora da escola onde leciono para desenvolver um projeto sobre a vida e a obra do compositor e cantor nordestino Luiz Gonzaga do Nascimento com os estudantes dos cursos integrados (técnico e médio) da escola Professor Agamemnon Magalhães. À época, estávamos vivenciando em todo Brasil os 100 anos do artista. De pronto, aceitei a proposta e me coloquei a planejar com a finalidade de inserir, mediante a efetivação desse projeto, os alunos no mundo de Luiz Gonzaga e desenvolver competências ligadas à fala e à escrita em língua materna, além de outros aspectos relacionados à linguagem. 
Partindo dessas motivações iniciais, comecei a desenvolver um projeto a fim de estabelecer as etapas que norteariam o desenvolvimento das diligências que levariam à culminância e êxito do trabalho pedagógico. Assim, busquei apoio nas pesquisas e reflexões desenvolvidas no campo da Linguística Aplicada por Kleiman (1995), Antunes (2003), Bakhtin (2006), Schneuwly e Dolz (2010), a fim de dar ao projeto fundamentação teórica consistente, uma vez que todo o objetivo de ensinoaprendizagem requer a escolha de uma teoria que norteie as atividades a serem realizadas.

O marco teórico foi estabelecido segundo parâmetros relacionados às dificuldades percebidas em modalidades como falar e escrever identificadas em sala de aula, necessidade de colocar os alunos em contato com diferentes gêneros textuais e manifestações artísticas, e solucionar possíveis deficiências no âmbito da leitura e compreensão textual.

O projeto foi realizado durante os meses de maio e junho de 2011 e compreendeu a execução de várias atividades pelos alunos que receberam orientações advindas do professor responsável pelo projeto e de outros docentes que se envolveram direta ou indiretamente com os trabalhos. Nos próximos capítulos, aprofundaremos a teoria, a metodologia de trabalho, a problematização e exporemos os resultados obtidos.

\section{2) Da fundamentação teórica}

Os parâmetros teóricos que deram suporte ao desenvolvimento deste projeto de intervenção encontram-se baseados numa perspectiva sociodiscursiva e dialógica da linguagem. Essa perspectiva teórica vê a língua como uma atividade em que sua verdadeira substância "não é constituída por um sistema abstrato de formas linguísticas nem pela enunciação monológica isolada, nem pelo ato psicofisiológico de sua produção, mas pelo fenômeno social da interação verbal" (Bakhtin, 2002:123). Nessa orientação, busca-se entender a língua fazendo sentido em situações concretas de uso por e para sujeitos em interação sociocomunicativa. Acrescemos ao escopo teórico, disponibilizado acima, reflexões que vêm dos estudos acerca dos processos de letramento.

A concepção de letramento adotada neste projeto é aquela desenvolvida por Kleiman (1995). Nessa perspectiva, letramento é entendido como "um conjunto de práticas sociais que usam a escrita, enquanto sistema simbólico e enquanto tecnologia, em contextos específicos, para objetivos específicos" (Kleiman, 1995:19). Assim, a escrita não se define, de acordo com essa abordagem, pelos processos de aquisição dos fundamentos do código da língua escrita, mas pelas práticas sociais que possibilitam a exposição do sujeito a uma série de eventos de letramento, ou seja, aos usos sociais que se faz da escrita.

Por gêneros textuais, entendemos que

$$
\begin{gathered}
\text { Revista Escrita } \\
\text { Rua Marquês de São Vicente, 225 Gávea/RJ CEP 22453-900 Brasil } \\
\text { Ano 2012. Número 15. ISSN 1679-6888. } \\
\text { escrita@puc-rio.br }
\end{gathered}
$$


todos os diversos campos da atividade humana estão ligados ao uso da linguagem. Compreende-se perfeitamente que o caráter e as formas desse uso sejam tão multiformes quanto os campos da atividade humana, o que, é claro, não contradiz a unidade nacional de uma língua. $\mathrm{O}$ emprego da língua efetua-se em forma de enunciados (orais e escritos) concretos e únicos, proferidos pelos integrantes desse ou daquele campo da atividade humana. Esses enunciados refletem as condições específicas e as finalidades de cada referido campo [...]. Evidentemente, cada enunciado particular é individual, mas cada campo de utilização da língua elabora seus tipos relativamente estáveis de enunciado, os quais denominamos gêneros do discurso (Bakhtin, 2006:261-262).

Os gêneros textuais ou discursivos medeiam o processo de interação verbal entre interlocutores de tal modo que podemos afirmar "que é impossível se comunicar verbalmente a não ser por algum gênero [...]" (Marcuschi, 2005:22). Todo texto pertence a um gênero textual, de modo que toda atividade comunicativa que se organiza em torno do texto verbal ou não verbal se insere em uma categoria genérica determinada por fatores linguísticos e extralinguísticos. Uma vez vinculados às atividades humanas, os gêneros textuais configuram o caráter diversificado dessas atividades. Esse aspecto, constitutivo desses dispositivos comunicacionais, confere uma condição maleável que permite aos gêneros se adequarem às situações e funções de uso.

No quadro do Interacionismo Sociodiscursivo, como postulado por Schneuwly e Dolz (2010), o gênero textual é entendido como um instrumento que possibilita a ação discursiva do sujeito engajado em atividades de linguagem. Ainda de acordo com esses autores, o gênero textual configura-se como um instrumento semiótico complexo que permite a produção e a compreensão de textos numa situação definida.

Assim, leitura e escrita não podem ser definidas tão somente por seus aspectos formais, uma vez que não constituem um fenômeno que se dá apenas no nível da língua, mas implica fatores do discurso que determinam sua forma e seu conteúdo. Além disso, a aprendizagem da tecnologia escrita e o desenvolvimento de competências de leitura e compreensão de texto encontram-se intrinsecamente ligados ao processo mais geral de interação verbal. Acerca da leitura, Antunes diz que essa atividade é "uma atividade de interação entre sujeitos e supõe muito mais que a simples decodificação dos sinais gráficos" (Antunes, 2003:67), de maneira que a atividade de leitura completa a atividade de escrita. No que diz respeito à atividade escrita, a autora afirma que toda escrita responde a um propósito funcional qualquer, isto é, possibilita a realização de alguma atividade sociocomunicativa entre as pessoas e está inevitavelmente em relação com os diversos contextos sociais em que essas pessoas atuam.

As atividades previstas no projeto possibilitaram aos estudantes o acesso a gêneros variados, como a música, a poesia, o texto teatral, e os múltiplos textos que circulam na internet. Além disso, durante a culminância do projeto, os estudantes puderam se expressar por meio de diferentes linguagens: representação teatral, dança e coro musical. Desse modo, pensamos que, inseridos em distintas práticas de letramento, 
os estudantes dos cursos integrados de Design de Interiores e de Manutenção e Suporte em Informática desenvolveram competências em leitura e escrita que talvez não fossem possíveis se o foco da aprendizagem de língua materna passasse apenas pela exposição do sistema abstrato da língua. Assumindo uma concepção de língua que passa pelos interlocutores, pelo gênero textual e pela situação de produção, estabelecemos os passos que nos levariam à concretização do objetivo geral: desenvolver habilidades e competências nos âmbitos da escrita e da leitura em contexto escolar.

\section{3) Do percurso}

A consecução de um projeto de letramento requer, além de um referencial teórico consistente, o estabelecimento das etapas que possibilitarão atingir o objetivo definido. Desse modo, construímos, junto aos estudantes, as atividades a serem desenvolvidas e o cronograma de execução dessas atividades.

Em um primeiro contato, reunimos os alunos e fizemos uma exposição detalhada do tema do projeto (Cem anos de Luiz Gonzaga: vida e obra), do objetivo geral e daquilo que esperávamos deles antes, durante e depois do desenvolvimento desse trabalho pedagógico. Nessa mesma ocasião, dividimos o grande grupo em grupos menores e delegamos uma tarefa que consistia na elaboração de sugestões de atividades a serem desenvolvidas ao longo do projeto.

Após discussão em grupo, os estudantes apresentaram as sugestões dos grupos que compreendiam pesquisas em bibliotecas e no ambiente virtual sobre Luiz Gonzaga, elaboração de painéis, viagem à cidade do cantor, elaboração de um quadro cronológico da vida do artista, apresentação de uma peça teatral, etc.

Filtramos as sugestões e elegemos aquelas que eram possíveis de serem realizadas levando em consideração as condições financeiras da escola, o tempo disponível dos estudantes e o tema e objetivo do projeto que visava o letramento dos estudantes inseridos em diferentes práticas de escrita e leitura.

Assim, estabelecemos que, ao longo de dois meses, intercalaríamos as atividades previstas para a sala de aula com as sugestões de trabalhos que foram consideradas mais adequadas ao desenvolvimento do tema e objetivo do projeto. Isso ficou assim organizado: I. Exposição em sala da vida e obra de Luiz Gonzaga; II. Leitura, compreensão e discussão sobre textos que tratam da obra do cantor a partir de rodas de leitura; III. Leitura, compreensão e discussão de temas tratados em suas músicas; IV. Resgate histórico da vida do artista em ambiente virtual; V. Apresentação de uma peça teatral no dia da festa de São João da escola. Definidas as tarefas a serem realizadas, passamos a um segundo momento que foi a construção ou escolha do texto a ser representado. Todas essas diligências foram realizadas pelos alunos sob orientação do 
docente responsável pelo projeto. A seguir, disponibilizamos uma imagem feita durante uma das rodas de leitura com os estudantes do $1^{\circ}$ ano do Ensino Médio do Curso de Manutenção e Suporte em Informática:

\section{Foto 1}

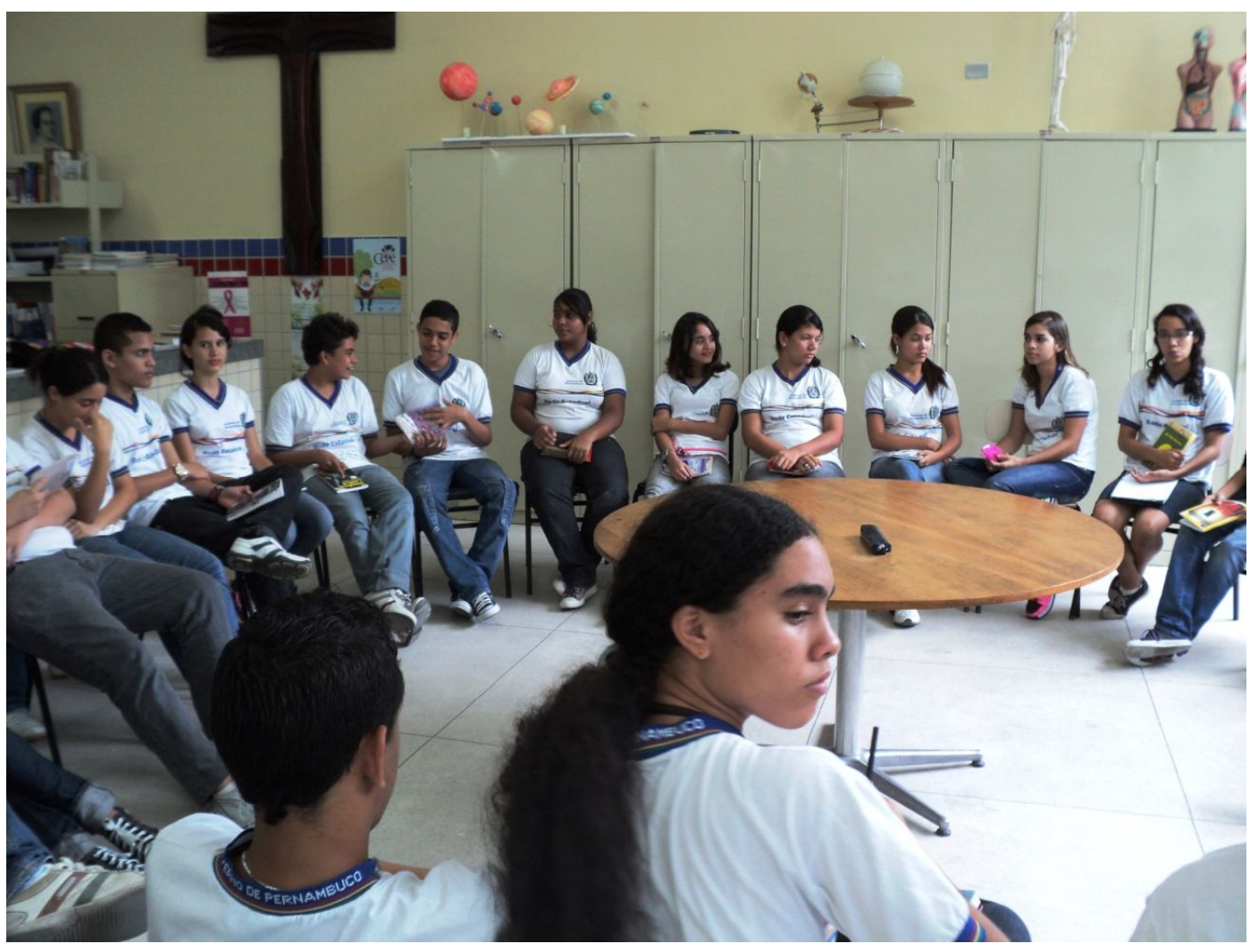

Foto: Luciano Azevedo

A peça teatral foi apresentada no dia da festa de São João da escola devido à estreita relação entre o tema do projeto, o artista pesquisado e as festividades juninas, bem como porque vislumbramos uma possibilidade de socialização entre os estudantes das impressões vivenciadas durante a peça teatral. $O$ espaço onde aconteceu a festa 
junina foi decorado com elementos que remetiam a Luiz Gonzaga, como composições e caricaturas.

\section{4) Problematizar e intervir}

Há questões que há muito se encontram no centro das preocupações da Linguística Aplicada e, embora tenham sido objeto de análise de vários trabalhos científicos como teses e dissertações, retornam às discussões recentes nesse campo de investigação. Essas questões, que concernem ao ensino e aprendizagem de língua materna, desdobram-se em muitas outras que ainda estão na agenda programática da Linguística Aplicada e compõem o acervo das suas preocupações. Nesses desdobramentos, identificamos os problemas relacionados à produção escrita e à leitura, ao uso do livro didático em sala de aula, aos objetos de ensino dispostos no material didático, à produção, avaliação e distribuição dos livros didáticos de línguas materna e estrangeira, ao trabalho com os gêneros textuais em situação escolar etc. Embora hoje, no Brasil, os trabalhos em Linguística Aplicada tenham se voltado para questões que envolvem a construção discursiva das identidades em diferentes situações de sala de aula, ainda é comum encontrarmos grupos de pesquisa que se debruçam sobre questões relativas ao ensinoaprendizagem de línguas a partir de novos construtos teóricos e metodológicos.

Em nossa experiência com alunos do ensino integrado da Escola Técnica Estadual Professor Agamemnon Magalhães, identificamos, durante o primeiro semestre de 2011, em turmas do $1^{\circ}$ ano, um déficit em relação à leitura e interpretação de textos, bem como à produção textual. Após observação criteriosa e uso de ferramentas como a avaliação diagnóstica e avaliação bimestral, concluímos que os estudantes, que há pouco haviam ingressado no Ensino Médio, apresentavam uma lacuna considerável em sua formação relativa ao Fundamental II. Essa lacuna não dizia respeito apenas ao conhecimento das estruturas gramaticais, mas se estendia a conhecimentos sobre os diferentes gêneros textuais e as estruturas que os concernem, assim como à leitura e compreensão de enunciados dentro de um arranjo textual complexo e que exige do estudante uma "leitura" dos aspectos intratextuais e extratextuais para a compreensão do sentido global do texto.

Assim, quando recebemos o convite da gestora da escola para desenvolver o projeto sobre a vida e a obra de Luiz Gonzaga, por ocasião das comemorações de 100 anos, vimos nisso uma oportunidade bastante salutar que nos ajudaria a intervir nos problemas identificados e amenizar os déficits que os estudantes apresentavam. De imediato, entendemos que o projeto traria contribuições efetivas ao desenvolvimento de competências linguísticas e discursivas e levaria esse estudante a conhecer a obra de um dos grandes compositores da nossa região Nordeste. Isso não significa que o projeto substituiria outras ações e atividades igualmente importantes no processo de ensinoaprendizagem de língua materna, como análise linguística, uso do material didático e 
aulas expositivas. Antes disso, pensamos no projeto como uma ferramenta pedagógica que nos ajudaria a inserir os alunos em diferentes práticas de letramento e, assim, amenizar ou solucionar deficiências que já deveriam ter sido superadas durante o percurso escolar que compreende o Fundamental I e II. Com essas ideias em mente e um arcabouço teórico-metodológico definido, demos início ao projeto.

\section{5) Relato de uma experiência}

Quando demos início ao projeto em sala de aula, os estudantes já cultivavam uma expectativa, uma vez que havíamos conversado sobre o projeto, semanas antes, quando ainda se encontrava em forma embrionária. A primeira atividade foi de cunho expositivo e configurou-se como uma apresentação, dialogada, acerca de Luiz Gonzaga. Por meio de estratégias que envolveram a conversa, a imagem e trechos de músicas, pudemos ativar os conhecimentos prévios que os estudantes tinham acerca do sertão, do baião - estilo musical explorado por Gonzaga -, do Nordeste e da vida de Luiz Gonzaga. Não foi difícil estabelecer um diálogo profícuo e marcado por intervenções oriundas dos estudantes que queriam contribuir ao mesmo tempo. Esse momento foi muito rico, pois ampliou a visão e o conhecimento dos estudantes acerca dos aspectos abordados em sala, ao passo que nos fez entrever uma gama de conhecimentos de que o estudante já dispunha. Nesse primeiro momento, expusemos o estudante ao gênero denominado exposição oral sem que nos detivéssemos em explicar seus aspectos formais e finalidade social. Além disso, os alunos também participaram da exposição mediante a apresentação de pontos de vista e dialogando entre si.

Ainda dentro dessa atividade, levamos, na aula seguinte, textos completos de músicas de Luiz Gonzaga que versavam sobre os problemas sociais que assolam a região Nordeste e pedimos que os alunos lessem e discutissem em pequenos grupos. Depois, pedimos um posicionamento crítico acerca dos problemas sociais que as letras apresentavam. Em seguida, as impressões compartilhadas pelos grupos foram socializadas com toda a turma. Por fim, cantamos "Asa Branca" e encerramos esse primeiro círculo de atividades que corresponde ao eixo I estabelecido em nossa metodologia.

Motivados nos primeiros encontros a conhecer mais sobre a vida e a obra do Rei do Baião, os estudantes deram continuidade às suas pesquisas nos laboratórios de informática da escola. Sob orientação docente, vasculharam páginas que traziam informações relevantes e, assim, assumiram certa autonomia em relação aos conteúdos de pesquisa, posto que selecionaram sites e conteúdos, entre tantos que circulam no universo virtual, de maneira responsável. As informações foram novamente socializadas em sala de aula e acrescentaram conhecimentos aos já existentes. Durante a execução dessa atividade, os alunos entraram em contato com um número bastante diversificado 
de gêneros digitais, dialogaram com os diferentes autores dos textos lidos, trocaram informações e participaram de novas práticas de letramento.

Ao término dessa experiência, elaboramos pequenos livretos com o material coletado pelos estudantes. A ideia era que pudéssemos organizar o material que, na maioria das vezes, encontra-se disperso na internet e facilitar o acesso da turma a diferentes fontes de informação. Na realização dessa atividade, consideramos que os estudantes acessaram sítios distintos na internet e coletaram informações diversas. A produção do livreto facilitou a circulação dessas informações e permitiu aos estudantes vivenciarem a produção de um livro. Como já foi dito, essa experiência foi vivenciada na biblioteca da escola sob orientação docente e da bibliotecária e aparece ilustrada na foto 1 .

A culminância do projeto viria com a apresentação da peça teatral no auditório da escola e a festa junina na quadra poliesportiva. A primeira diligência a ser atendida foi a elaboração e/ou escolha do texto a ser representado. Esse quesito ficou sob a responsabilidade de dois alunos do Curso de Manutenção e Suporte em Informática que também se dedicam ao teatro e frequentam um curso de artes cênicas. Após conseguirem um texto com o seu professor de teatro, nos vimos diante de um novo desafio que era o de adaptá-lo. O original era extenso e precisávamos fazer cortes consideráveis no texto porque não dispúnhamos de muito tempo para ensaios e apresentação. Novamente fomos salvos pelo conhecimento em técnicas de teatro dos referidos estudantes. Feito isso, demos início aos ensaios que aconteceram no auditório da escola durante os intervalos do meio-dia. A foto abaixo ilustra o que acabamos de expor:

\section{Foto 2}




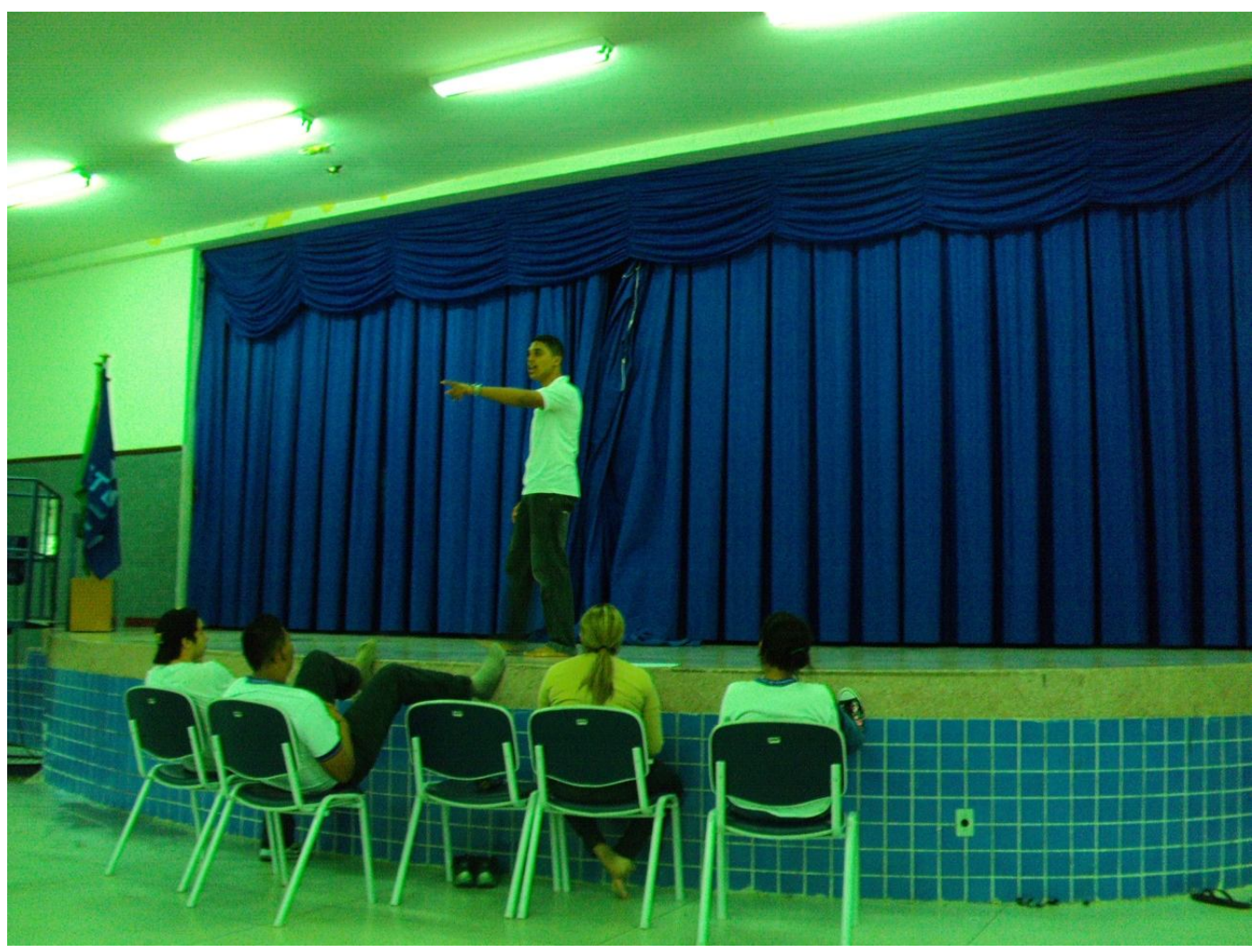

Foto: Luciano Azevedo

$\mathrm{Na}$ foto, vemos o texto adaptado assumindo vida nos gestos e na voz de um estudante do Curso de Manutenção e Suporte em Informática enquanto os demais observavam a fim de avaliarem a "performance" do colega.

A inclusão de outras formas de expressão artística foi vista com bons olhos pelos estudantes, de maneira que resolvemos enxertar na narrativa um coral e um número de dança. Assim, enquanto os atores encenavam o texto teatral, os demais estudantes cantavam e dançavam músicas do centenário Luiz Gonzaga. A seguir, foto do ensaio do coral que foi regido por um estudante do Curso de Informática:

Foto 3 


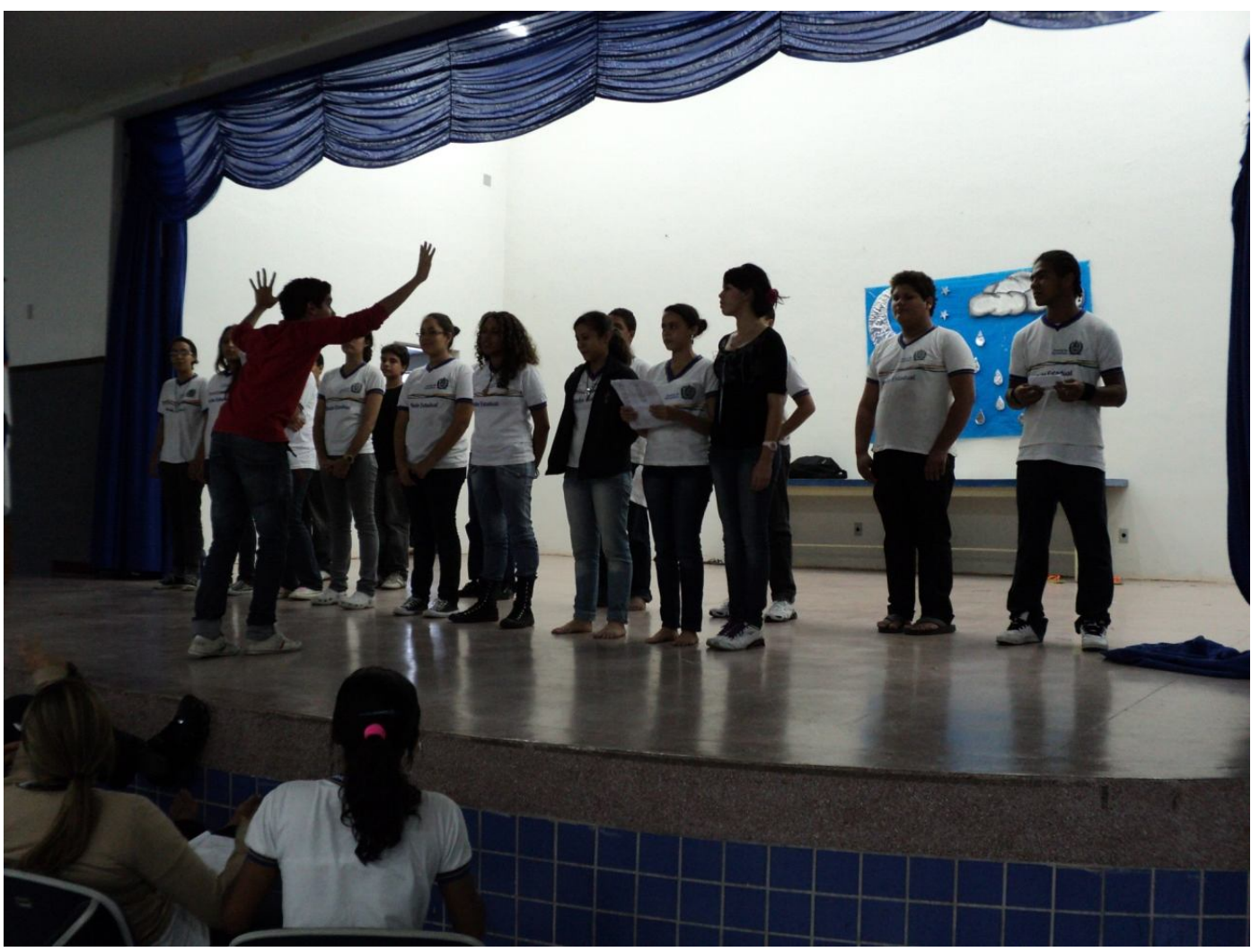

Foto: Luciano Azevedo

Enquanto os ensaios aconteciam no auditório da escola, estudantes do Curso de Design de Interiores trabalhavam nos laboratórios de desenho e produziam o cenário a ser usado na peça teatral. Salientamos que essa atividade foi tão importante quanto as demais no tocante à inserção dos falantes em práticas de letramento, uma vez que a situação permitiu aos estudantes a discussão sobre o material a ser providenciado, o design dos objetos, as cores empregadas etc. Ao longo das tarefas, os estudantes recorreram ao texto teatral e às músicas, a fim de ajustar o cenário ao todo do evento. Por outro lado, aqueles responsáveis pela peça consultaram os estudantes envolvidos na produção do cenário para dizer como deveriam proceder e quais objetos deveriam ser produzidos. Assim, eles puderam se inserir em diferentes práticas de letramento que concernem àquelas mediadas pelo texto impresso, bem como àquelas que encontram apoio no texto oral. Essa experiência também foi registrada e pode ser visualizada na foto seguinte: 
Foto 4

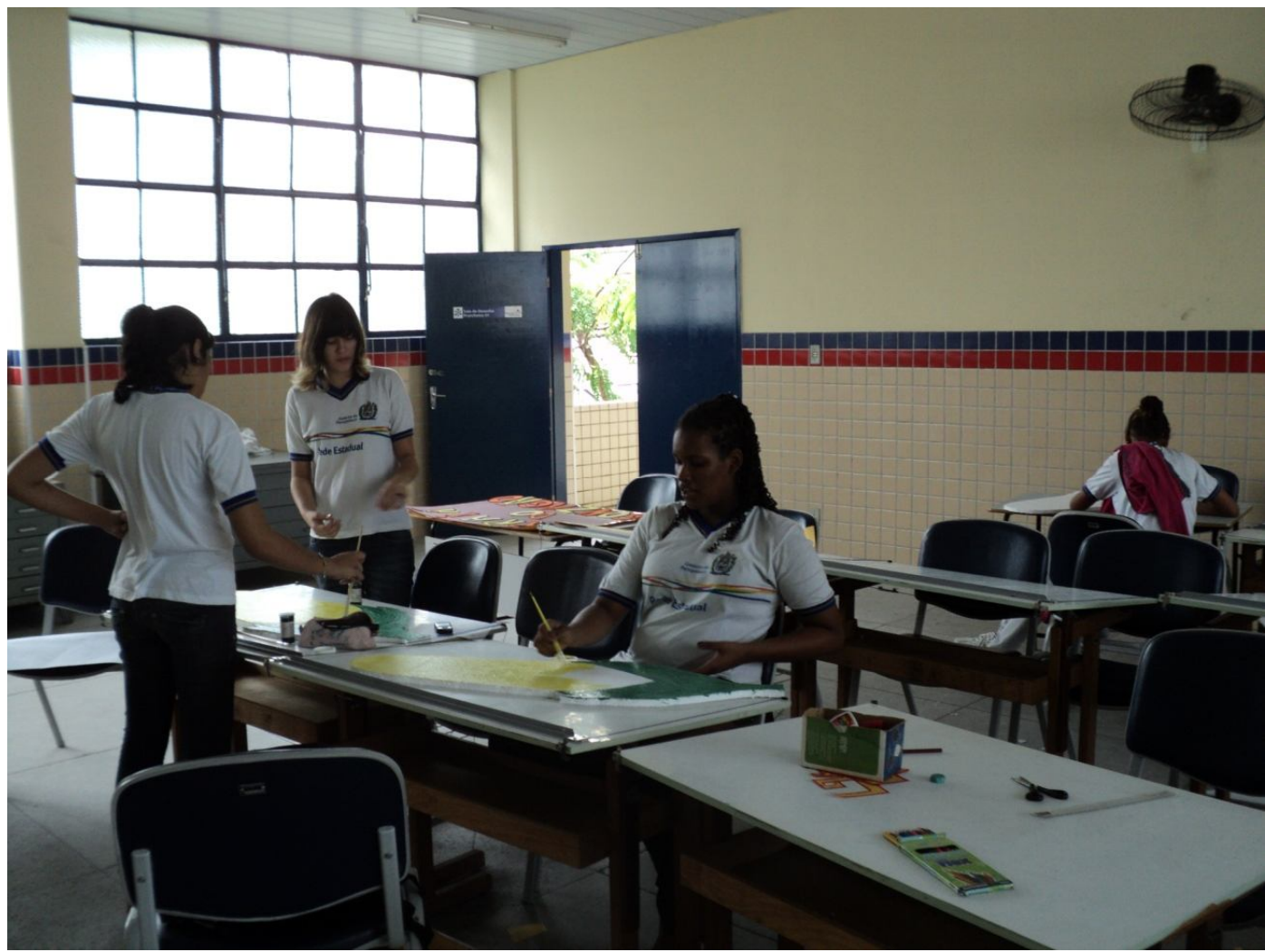

Foto: Luciano Azevedo

No dia da apresentação, era grande a ansiedade de todos os envolvidos. Estávamos há tanto tempo convivendo com Luiz Gonzaga e construindo maneiras de estudá-lo e compartilhar conhecimentos acerca da sua obra que não queríamos conter nossa emoção em vivenciá-lo no palco e na festa junina. E foi com esse ímpeto que demos início às apresentações do Projeto Musical Luiz Gonzaga Canta o Sertão Nordestino.

Através do texto e performances emocionadas, o grupo falou da esperança nunca ausente no coração do sertanejo e das dores e desilusões que enfrenta quando encara o chão rachado, a seca que se prolonga, as necessidades não saciadas e as promessas não cumpridas de políticos descomprometidos. A peça viajou por esses caminhos feitos de olhos que se voltam para o céu em busca de ajuda e proteção divina e pés que pisam o chão da mais dura realidade. Diante disso, só resta um desejo: deixar o sertão e buscar em terras estranhas a dignidade que não sobrevive em meio a tanta solidão e penúria. Embora tenha os pés fincados nessa terra que já não dá frutos nem flores, o sertanejo quer salvar ao menos a alma se já não pode salvar o corpo minguado que definha entre os gravetos ressequidos da caatinga.

Alinhados e conservando um sincronismo que os colocou numa sintonia que beirava a perfeição, os alunos da ETEPAM mostraram que o teatro, a música e a dança 
são instrumentos indispensáveis de reflexão, encantamento e representação emocionada da realidade.

\section{Foto 5}

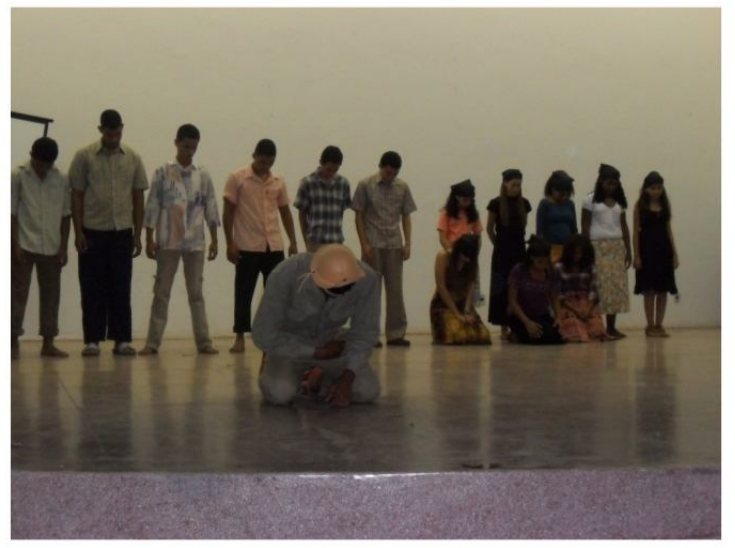

Foto: Analice Rocha

Deixamos o auditório e nos dirigimos à quadra poliesportiva da escola após a apresentação da peça teatral. Lá, os alunos também puderam vivenciar experiências com o texto que passaram pela quadrilha junina e suas canções peculiares e as letras de Luiz Gonzaga espalhadas pelas paredes do ginásio. Bastante apreciada no Nordeste brasileiro, a festa junina possibilita ao estudante entrar em contato com uma variedade da língua que é socialmente desprivilegiada, mas que ganha centralidade e importância nesse período junino e que é pejorativamente chamada de caipira.

A interação entre os estudantes durante todo o processo de desenvolvimento do projeto de letramento foi um dos aspectos que merece destaque neste relato. Ao longo dos trabalhos, os estudantes vivenciaram diferentes situações em que a interação comunicativa foi praticada e redimensionada quando pensamos nas situações tradicionais de sala de aula em que a comunicação se dá como se fosse uma via de mão única, ou seja, apenas o professor fala e aos estudantes cabe ouvir, memorizar e reproduzir. Pensando nesse aspecto constitutivo da língua, elegemos uma concepção 
interacionista da linguagem e perseguimos a evidência de que as línguas só existem para promover a interação entre as pessoas, como pode ser observado em Antunes (2003). Essa concepção da língua-em-função perpassou todas as atividades executadas ao longo do projeto de maneira que a língua deixou de ser, para os estudantes, algo estático e destituído de dinamismo e passou a representar um patrimônio produtivo e relevante da espécie humana.

\section{Foto 6}

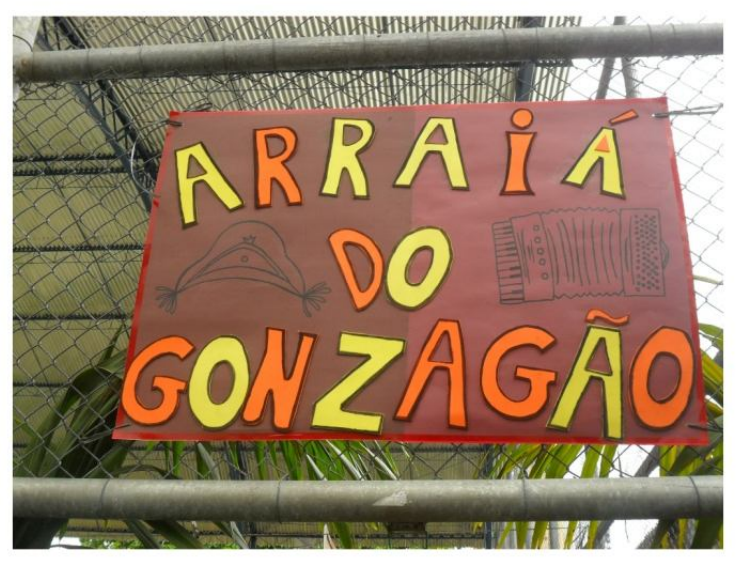

Foto: Analice Rocha

\section{6) Conclusão}

O ensino-aprendizagem de língua portuguesa, segundo propostas feitas no campo da Linguística Aplicada, reclama um novo modo de abordagem dos conteúdos constantes das matrizes curriculares e exige a inclusão de outros objetos de conhecimento que devem ser considerados a partir de diferentes matizes. A aprendizagem de uma língua, seja a materna ou outra qualquer, não deve ser reduzida à memorização de elementos dessa língua nem de quadros de referência que trazem as classes gramaticais, por exemplo. Aprender uma língua é, antes de tudo, desenvolver competências e habilidades linguísticas que tornarão o falante apto a agir em diferentes contextos sociais. A reflexão sobre a língua requer que contextos de uso sejam criados 
dentro e fora da sala de aula para que o falante entenda que as possibilidades de uso vão muito além daquelas espremidas pelos muros estreitos da escola.

\section{Referências Bibliográficas}

ANTUNES, I. Aula de português: encontro e interação. São Paulo: Parábola Editorial, 2003.

BAKHTIN, Mikhail. Estética da criação verbal. 4a ed. São Paulo: Martins Fontes, 2006.

KLEIMAN, A. Os significados do letramento: uma nova perspectiva sobre a prática social da escrita. $6^{\text {a }}$ ed. Campinas, São Paulo: Mercado de Letras, 1995.

MARCUSCHI, L. A. Produção textual, análise de gêneros e compreensão. São Paulo: Parábola Editorial, 2008.

SCHNEUWLY, B.; DOLZ, J. Gêneros orais e escritos na escola. Campinas, São Paulo: Mercado de Letras, 2010. 